Same-day and delayed reports of pain intensity in second-trimester medical termination of pregnancy : a brief report

\title{
Mentula, M.
}

2014-12

Mentula , M , Kalso , E \& Heikinheimo , O 2014 , ' Same-day and delayed reports of pain intensity in second-trimester medical termination of pregnancy : a brief report ' , Contraception , vol. 90 , no. 6 , pp. 609-611 . https://doi.org/10.1016/j.contraception.2014.06.031

http://hdl.handle.net/10138/310301

https://doi.org/10.1016/j.contraception.2014.06.031

publishedVersion

Downloaded from Helda, University of Helsinki institutional repository.

This is an electronic reprint of the original article.

This reprint may differ from the original in pagination and typographic detail.

Please cite the original version. 


\title{
Same-day and delayed reports of pain intensity in second-trimester

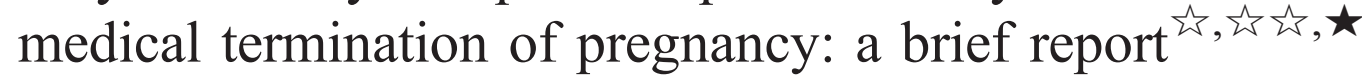

\author{
M. Mentula ${ }^{\text {a }}$, E. Kalso ${ }^{\text {, O. Heikinheimo }}{ }^{\text {a,* }}$ \\ ${ }^{\mathrm{a}}$ Department of Obstetrics and Gynecology, University of Helsinki and Helsinki University Central Hospital, Helsinki, Finland \\ ${ }^{\mathrm{b}}$ Pain Clinic, Department of Anesthesiology, Intensive Care Medicine, Emergency Medicine and Pain Medicine, Helsinki University Central Hospital and \\ Institute of Clinical Medicine, University of Helsinki, Helsinki, Finland \\ Received 11 March 2014; revised 15 June 2014; accepted 17 June 2014
}

\begin{abstract}
Objective: To assess same-day and delayed reports of pain intensity during and after second-trimester medical termination of pregnancy (MTOP).

Study Design: A prospective randomized trial (217 women) comparing 1- and 2-day mifepristone-misoprostol intervals.

Results: Women reported intense pain [median visual analogue scale (interquartile range)] related to expulsion of the fetus [6 (0-10)]. Delayed reports of maximal pain described the pain as more intense than same-day reports [8 (3-10) vs. $7(1-10)$, p<.001].

Conclusions: Most women reported and readily remembered intense pain associated with fetal expulsion during second-trimester MTOP. Implications: Adequate, properly timed pain management during second-trimester MTOP is crucial.

(C) 2014 Elsevier Inc. All rights reserved.
\end{abstract}

Keywords: Second trimester abortion; Medical abortion; Visual analogue scale; Pain; Recollection

\section{Introduction}

Medical termination of pregnancy (MTOP) is associated with more pain than surgical procedures performed under general anesthesia [1]. This pain becomes more intense with advancing gestation, and during second-trimester MTOP, the maximum pain has been moderate to severe [1-3].

MTOP is widely used, safe and very little dependent on the skills of the medical staff performing it $[1,4,5]$. Pain relief during the procedure needs attention, and studies on pain management during second-trimester medical TOP are sparse [6]. This study assessed pain intensity during or after second-trimester MTOP and delayed reports of pain 2-4

\footnotetext{
Funding: Helsinki University Central Hospital research funds.

论败 Conflict of interest: None of the authors have conflicts of interest regarding this article.

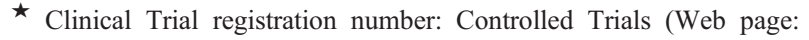
http://www.controlled-trials.com/ISRCTN09944151).

* Corresponding author at: Department of Obstetrics and Gynecology, Kätilöopisto Hospital, Helsinki University Central Hospital, P.O. Box 610, 00029-HUS, Helsinki, Finland.

E-mail address: oskari.heikinheimo@helsinki.fi (O. Heikinheimo).
}

weeks after. Factors affecting the experience of pain were investigated.

\section{Materials and methods}

These data were derived from a prospective randomized trial of 227 women comparing 1- and 2-day mifepristonemisoprostol interval in second-trimester MTOP at Helsinki University Central Hospital between 2008 and 2010 [2]. The trial had approvals from the Ethics Committee of the Hospital District of Helsinki and Uusimaa, and the Finnish National Agency for Medicines.

MTOP was performed using a 200-mg dose of mifepristone and 400-mcg repeat doses of misoprostol. During misoprostol administration, women were in-patients until abortion. Pain during MTOP was managed with the following:

1. A prophylactic dose of oral paracetamol $(500 \mathrm{mg})$ plus dihydrocodeine $(10 \mathrm{mg})$ and ibuprofen $(600-800 \mathrm{mg})$ with first misoprostol dose

2. First-line analgesics: ibuprofen (up to $1800 \mathrm{mg}$ per day) on request 
3. Opioids on request: oxycodone hydrochloride (4 $\mathrm{mg}$ iv; $10 \mathrm{mg}$ po), pethidine hydrochloride $(50-75 \mathrm{mg})$ or tramadol hydrochloride (50-100 mg)

4. Ibuprofen up to a dose of $1800 \mathrm{mg}$ per day at home on request

Pain was assessed using a numerical visual analogue scale (VAS) of 0 (no pain) to 10 (the worst possible pain one could imagine) before administration of each dose of mifepristone, misoprostol or analgesics. At a follow-up assessment (2-4 weeks after), VAS scores for pain at home and at the followup visit, as well as the use of analgesics at home were asked. The highest pain VAS scores were reported and classified into various time periods as follows:

1. Before first misoprostol dose (at the onset of first misoprostol dose)

2. Before fetal expulsion (during repeat doses of misoprostol)

3. Around fetal expulsion ( $30 \mathrm{~min}$ before and during fetal expulsion)

4. After fetal expulsion (10 min or more after fetal expulsion)

5. At home

6. At the follow-up visit

The women were asked to rank their satisfaction with the overall treatment of pain during MTOP with a scale of 4-10 (poor to excellent).

\section{Statistical analysis}

PASW 18.0 for Mac (SPSS Inc., Chicago, IL, USA) was used for statistical analysis. Nonparametric data are presented as medians [interquartile range (IQR)]. Differences in continuous variables were analyzed by using the Mann-Whitney $U$, Wilcoxon and Friedman tests, as appropriate. Statistical significance was defined as $\mathrm{p}<.05$.

\section{Results}

This analysis involved 217 women, and one-fifth of patients did not attend the follow-up visit [2]. The 1-day mifepristonemisoprostol interval group had more women with previous vaginal deliveries, less evacuations of placenta and less repeat misoprostol doses than the 2-day group (Table 1).

Reports of intense pain were related to expulsion of the fetus (Fig. 1). The reported VAS scores before the first misoprostol dose or during repeat misoprostol administration were low, until shortly before fetal expulsion $(p<.001)$. Similarly, after fetal expulsion, at home or at the follow-up visit, the pain VAS scores were low.

The maximal same-day VAS score [median (interquartile range, or IQR)] during second-trimester MTOP was 7 (5-8). However, the reported delayed maximal VAS score, queried at the follow-up visit, was higher $[8(7-10, p<.001)]$.
Table 1

Demographics of the 217 women undergoing second-trimester MTOP during 2008 to 2010

\begin{tabular}{|c|c|c|}
\hline Variable & $\begin{array}{l}\text { 1-day }{ }^{\text {a }} \text { group, } \\
n=114(52.5)\end{array}$ & $\begin{array}{l}\text { 2-day }{ }^{\text {a }} \text { group, } \\
n=103(47.5)\end{array}$ \\
\hline Weeks of gestation & $15(14-17)$ & $16(14-18)$ \\
\hline Age (years) & $24(21-29)$ & $23(20-29)$ \\
\hline \multicolumn{3}{|l|}{ Marital status } \\
\hline Married or cohabiting & $35(30.7)$ & $35(34.0)$ \\
\hline Single & $79(69.3)$ & $68(66.0)$ \\
\hline \multicolumn{3}{|l|}{ Socioeconomic status } \\
\hline White-collar workers & $11(9.6)$ & $13(12.6)$ \\
\hline Blue-collar workers & $40(35.1)$ & $37(35.9)$ \\
\hline Students & $29(25.4)$ & $25(24.3)$ \\
\hline Others & $34(29.8)$ & $28(27.2)$ \\
\hline Body mass index $\left(\mathrm{kg} / \mathrm{m}^{2}\right)$ & $23(21-26)$ & $23(20-25)$ \\
\hline \multicolumn{3}{|l|}{ Previous pregnancies } \\
\hline Termination of pregnancy & $54(47.4)$ & $44(42.7)$ \\
\hline Vaginal deliveries & $38(33.3)$ & $25(24.3)$ \\
\hline Smoking & $66(57.9)$ & $66(64.1)$ \\
\hline \multicolumn{3}{|l|}{ Indication for TOP } \\
\hline Fetal & $7(6.1)$ & $8(7.8)$ \\
\hline Social & $107(93.9)$ & $95(92.2)$ \\
\hline Induction-to-abortion time (hours) & $8(6-12)$ & $7(5-9)$ \\
\hline $\begin{array}{l}\text { Evacuation of placenta during TOP } \\
\quad \text { (under general anesthesia) }\end{array}$ & $29(25.4)$ & $39(37.9)$ \\
\hline \multicolumn{3}{|l|}{$\begin{array}{l}\text { Number of misoprostol doses } \\
\text { before fetal expulsion }\end{array}$} \\
\hline $1-3$ & $61(53.5)$ & $38(36.9)$ \\
\hline 4 or more & $53(46.5)$ & $65(63.1)$ \\
\hline \multicolumn{3}{|l|}{ Route of misoprostol administration } \\
\hline Mostly vaginal & $106(93.0)$ & $95(92.2)$ \\
\hline Mostly oral or sublingual & $8(7.0)$ & $8(7.8)$ \\
\hline
\end{tabular}

Data are presented as $n(\%)$ or median (IQR).

${ }^{\mathrm{a}}$ Mifepristone-misoprostol interval (per protocol).

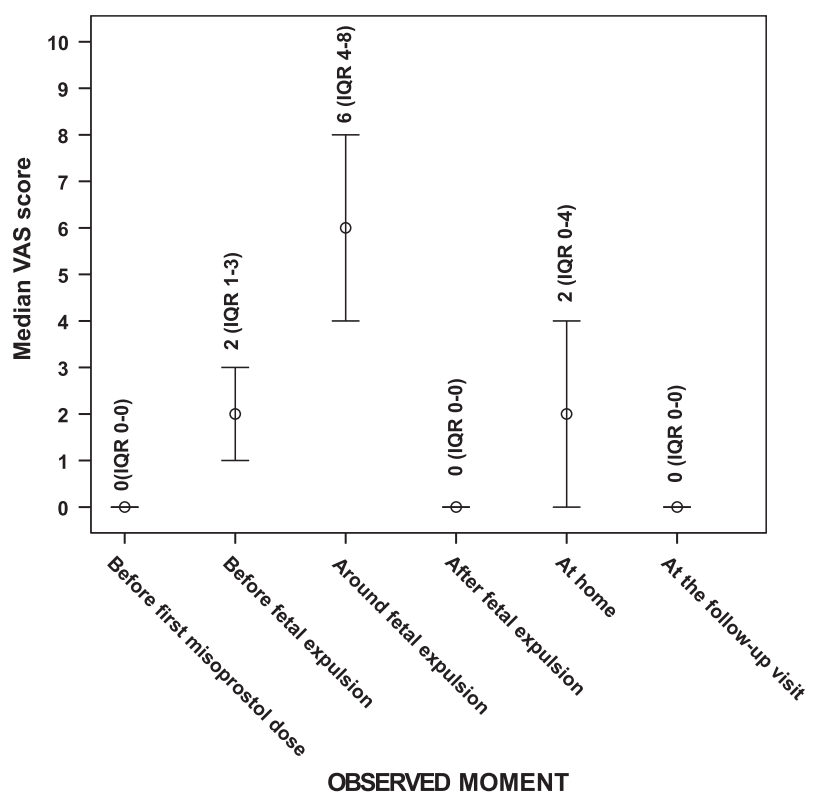

Fig. 1. Reported median pain intensity scores on a numerical VAS (VAS 0-10) among 217 women undergoing second-trimester MTOP. Data are shown as median maximum VAS scores and interquartile ranges at observed time points. 
The effect of various demographic factors (Table 1) on reported pain was analyzed. Maximal pain VAS scores [median (IQR)] were higher among women under 25 years old compared to older women [7 (5-8) vs. $6(5-8), \mathrm{p}=.047$ ], and in women without previous vaginal deliveries compared to those having previous vaginal deliveries [7 (5-8) vs. $5(3-8)$, $\mathrm{p}=.002]$. Maximal pain VAS scores were lower in the 1-day than in the 2-day mifepristone-misoprostol interval group [6 (5-8) vs. $7(5-9), p=.038]$ and among women with the highest socioeconomic status (white-collar workers) compared to others [5 (3-7) vs. $7(5-8), \mathrm{p}=.006]$. Also, women undergoing MTOP for fetal indications had lower VAS scores than women undergoing MTOP for social indication [4 (2-6) vs. 7 (5-8), p=.005].

None of the patients declined analgesics; few $(9.2 \%)$ managed without additional opiates. The number of additional opioid doses [median (IQR)] was 2 (1-2). Most women (97.4\%) found NSAID medication at home adequate and did not request opioids. Most women were satisfied with the treatment of pain on the ward, and the satisfaction rate [median (IQR)] was 8 (7-9).

\section{Discussion}

Women reported moderate to severe pain (median VAS over 6) associated with fetal expulsion during second-trimester MTOP. Based on questioning 2-4 weeks after the MTOP procedure, this pain is readily and intensely remembered.

This study provides new information on timing and risk factors for experiencing pain and the recollection of pain in second-trimester MTOP. However, in this secondary analysis, the analgesics and their dosing varied. The duration of pain could not be analyzed, and there is a small risk that the most intense pain scores are lacking. The study sample is too small to evaluate the impact of all demographic characteristics.

However, our results indicate that intense pain marks the point of fetal expulsion, and analgesics should be given frequently at that time. The finding of intense recollection of severe pain is worrying. How does this experience affect future plans for pregnancy and childbirth?

In conclusion, most women report moderate to severe pain during second-trimester MTOP. Thus, more intense and liberal use of analgesics during intense or increasing pain is needed. The more severe the pain becomes, the more difficult it may be to get it under control. Further studies are needed to optimize the prevention and treatment of pain.

\section{References}

[1] Lohr PA, Hayes JL, Gemzell-Danielsson K. Surgical versus medical methods for second trimester induced abortion. Cochrane Database Syst Rev 2008;1:CD006714.

[2] Mentula M, Suhonen S, Heikinheimo O. One- and two-day dosing intervals between mifepristone and misoprostol in second trimester medical termination of pregnancy — a randomized trial. Hum Reprod 2011;26(10):2690-7.

[3] Hamoda H, Ashok PW, Flett GMM, Templeton A. Analgesia requirements and predictors of analgesia use for women undergoing medical abortion up to 22 weeks of gestation. BJOG 2004;111 (9):996-000.

[4] Finnish National Institute for Health and Welfare. Reproduction. Available from: http://www.stakes.fi/EN/tilastot/statisticsbytopic/ reproduction/index.htm2011 [Accessed 19 November 2013].

[5] Abortion Statistics England and Wales: 2010. 2011 May 1:1-42. Available from: https://www.gov.uk/government/uploads/system/ uploads/attachment_data/file/147288/dh_127202.pdf.pdf [Accessed 19 November 2013].

[6] Jackson E, Kapp N. Pain control in first-trimester and second-trimester medical termination of pregnancy: a systematic review. Contraception 2011;83(2):116-26. 